\title{
Wrestling with Masculinity: Messages about Manhood in the WWE
}

\author{
Danielle M. Soulliere
}

Published online: 7 November 2006

(C) Springer Science + Business Media, Inc. 2006

\begin{abstract}
This study was designed to examine messages about manhood revealed by televised professional wrestling through content analyses of 118 World Wrestling Entertainment (WWE) programs and pay-per-view events. Specifically, messages concerning masculinity and the way in which proof and assertion of manhood are accomplished were investigated and compared to the culturally ideal version of masculinity. Findings revealed that the messages imparted by the WWE about manhood support the dominant hegemonic form of masculinity, which emphasizes aggression and violence, emotional restraint, and success and achievement. Popular culture messages about manhood that emphasize hegemonic masculinity have implications for alternative expressions of masculinity and potential gender role socialization, which are discussed.
\end{abstract}

Keywords Masculinity · Professional wrestling .

Popular culture

Gender is a cultural creation (Butler, 1995; Gilmore, 1990; Kimmel, 1990) that is often constructed by and represented through popular culture media (Gauntlett, 2002) such as advertisements (Andersen, 1997; Basow, 1992; Beal, 1994; Witt, 2000), music (Andersen, 1997; Witt, 2000), sports (Hanke, 1998; Messner, Hunt, \& Dunbar, 2001), and entertainment television (Andersen, 1997; Spangler, 1992; Witt, 2000). Indeed, Andersen (1997) asserted that the mass media, in its various forms, is loaded with gendered presentations, and Gauntlett (2002) has maintained that

D. M. Soulliere $(\square)$

Department of Sociology \& Anthropology,

University of Windsor, 401 Sunset Avenue,

Windsor, ON, Canada N9B 3P4

e-mail: soulli6@uwindsor.ca the media are responsible for disseminating numerous messages about gender, including acceptable forms of femininity and masculinity.

It has been noted that television, in particular, is a powerful source of gender representations. As Spangler (1992) has argued, television provides models of appropriate gender roles and behavior, and effectively constructs ideals of femininity and masculinity. Similarly, Witt (2000) contended that television, through both entertainment programming and advertisements, sends uniquely compelling messages about socially approved roles for boys and girls and men and women.

Research concerning gender and popular culture media has tended to focus on women rather than men (Durkin, 1985; Good, Porter, \& Dillon, 2002; Scharrer, 2001; Vigorito \& Curry, 1998). Vigorito and Curry (1998), for example, reported that only recently has attention been given to men and masculinity in media studies of gender portrayals. Durkin (1985) also contended that most research on gender in the media has focused on the construction of femininity; masculinity has received only a cursory nod by default. Nevertheless, Hanke (1998) pointed to more recent media studies that focus on popular representations of masculinity in film, television, mediated sports, advertising, and popular music.

Studies reveal that gender stereotypes abound in popular culture media representations (Andersen, 1997; Anderson \& Hamilton, 2005; Basow, 1992; Dietz, 1998; Ditsworth, 2001; Evans \& Davies, 2000; Ganahl, Prinsen, \& Netzley, 2003; Gooden A. M. \& Gooden M. A., 2001; Ogletree, Martinez, Turner, \& Mason, 2004; Seidman, 1999; Towbin, Haddock, Zimmerman, Lund, \& Tanner, 2003; Witt, 2000). For example, Andersen (1997) made note of the sexism found in popular culture representations, especially television, and argued that women and men are 
portrayed in stereotypical ways. Likewise, Ditsworth (2001) pointed to the gender misrepresentations and stereotypes commonly found in popular children's programming, whereas Towbin et al. (2003) have noted the persistence of gender stereotypes in feature-length animated Disney films. Moreover, gender stereotypes have been noted in video games (Dietz, 1998), children's literature (Anderson \& Hamilton, 2005; Clark, Guilmain, Saucier, \& Tavarez, 2003; Diekman \& Murnen, 2004; Gooden A. M. \& Gooden M. A., 2001), and elementary school textbooks (Evans \& Davies, 2000), which suggest that the media present particular forms of femininity and masculinity. To be sure, Craig (1992) has argued that popular television situation comedies, such as Home Improvement, Coach, and Cheers, have routinely made use of gender stereotype parodies as a way of questioning traditional masculine and feminine values. Hanke (1998), however, has contended that the use of such gender parodies in television situation comedies serves to reiterate rather than to critique conventional masculinity and femininity.

Media studies that have focused on depictions of men and displays of masculinity generally indicate that a particular kind of masculinity is presented-primarily the dominant, culturally ideal, hegemonic form of masculinity (Craig, 1992, 1993; Evans \& Davies, 2000; Gauntlett, 2002; Hanke, 1992; Messner, 2000; Vigorito \& Curry, 1998). Hegemonic masculinity, which is considered the cultural ideal or normative definition of manhood in North American society, is primarily reflective of White, heterosexual, middle-class men (Connell, 1987; Dworkin \& Wachs, 2000; Kimmel, 1990, 1999) Vigorito and Curry (1998) reported, for example, that major reviews of the research on gender and the mass media support the hegemonic masculine ideal, and Hanke (1992) contended that popular culture media tend to showcase hegemonic masculinity and to subordinate alternative forms of masculinity. Gauntlett (2002) argued that despite changes in gender ideals, images of the conventional "macho man" still circulate in popular culture. In fact, there is evidence of asymmetrical change in popular culture gender role portrayals, with more change showing for women than for men (Diekman \& Murnen, 2004).

Some have argued that contemporary media representations of men and masculinity reflect the perceived growing ambiguity of gender roles in today's society (Craig, 1993; Gauntlett, 2002; Messner, 1987). Indeed, Gauntlett (2002) wrote about "masculinity in crisis," and asserted that the push of the "macho man" in popular culture media is essentially a reaction to the new "girl power" roles being carved out by women. Similarly, Messner (1987) suggested that mainstream popular culture media such as televised sports have projected images of men that emphasize conventional hegemonic masculinity as a way of delineat- ing clearer boundaries between men and women, thereby decreasing the ambiguity of contemporary gender roles.

The dominant hegemonic masculinity is associated with a number of characteristics that consistently appear in media presentations of men. Such characteristics include violence and aggression, emotional restraint, toughness, risk-taking, physical strength, courage, power and dominance, competitiveness, and achievement and success (Brannon, 1976; Brittan, 1989; Donaldson, 1993; Hopkins, 1996; Kaufman, 1995; Nicholson, 1993; Schoenberg, 1993; Thompson, 1991; Toch, 1998).

In particular, presentations of men in mediated sports continue to reflect and reaffirm the traditional hegemonic notion of masculinity and its attending characteristics (Dworkin \& Wachs, 2000; Messner, 1992, 2000; Sabo \& Panepinto, 1990). For example, Messner (2000) noted that televised sports and their accompanying commercials consistently present the mostly male audience with a narrow portrait of masculinity, by emphasizing such characteristics as violence and aggression, power and dominance, and success and achievement. Messner et al. (2001) further maintained that sports programming sends uniquely powerful messages that support the characteristics of hegemonic masculinity. Researchers who have analyzed masculinity displays within sport have concluded that sport presentations typically embody the traits most associated with the dominant masculinity, such as aggression, domination, toughness, risk-taking, physical strength, and competition (Koivula, 2001; Messner et al., 2001; Thornton, 1993).

Although largely discounted as a legitimate sport (Atkinson, 2002), professional wrestling is a form of popular culture entertainment that is at least conceptually comparable to professional sports such as football, hockey, and soccer (Atkinson, 2002; Schnirring, 2000). Whether "sport" or "entertainment," professional wrestling has achieved a certain venerable status in North American popular culture, as an estimated 35 to 50 million people tune in to watch professional wrestling programs each week in the United States (Ashley, Dollar, Wigley, Gillentine, \& Daughtrey, 2000; Atkinson, 2002; Rosellini, 1999). World Wrestling Entertainment (WWE) programs consistently rank among the most popular in weekly television ratings (Albano, Sugar, \& Woodson, 1999; Ashley et al., 2000), and consistently rank among the top-grossing pay-per-view events (Haley, 2003). As both a pseudo-sport and part of mainstream entertainment popular culture, the messages concerning masculinity presented by televised professional wrestling may serve as important cultural indicators of what being a man is all about.

Although there have been few scholarly investigations into gender roles or masculinity in professional wrestling (see Cherry, 2002; Soulliere, 2005), some noteworthy 
commentaries suggest that professional wrestling presents masculinity primarily in its culturally ideal form (Atkinson, 2002; Cherry, 2002; Communication Studies 298, 2000; Jhally \& Katz, 2002; Mazer, 1998; Soulliere, 2005; Stroud, 2001). In their video Wrestling with Manhood, Jhally and Katz (2002) argued that professional wrestling glamorizes the dominant form of masculinity by emphasizing physical size, strength, and aggression. Butryn (2003) commented that the video's central premise is that wrestling franchises such as the WWE embody "a particular narrative of hegemonic masculinity, in which bullying, intimidation, humiliation, and sexual violence are all intertwined into an acceptable template for male behavior" (p. 488). Likewise, the Communication Studies 298 research team (2000) found evidence of a hegemonic masculinity in professional wrestling displays that emphasize strength, toughness, aggression, violence, and dominance. In her textual analysis of Wrestlemania events, Cherry (2002) similarly found the dominant masculinity to be strong in professional wrestling; themes of violence, strength through muscularity, toughness, emotional restraint, and athleticism were predominant. Moreover, in an earlier study of the way in which masculinity is constructed in professional wrestling, I (Soulliere, 2005) found a prevalence of characteristics associated with the hegemonic masculine ideal.

Stroud (2001) has contended that professional wrestling may be even more extreme in constructing masculinity than the so-called conventional sports. Messner et al. (2001) included professional wrestling in their analysis of sports and masculinity and found that messages about masculinity were most clear in the dramatic spectacle of professional wrestling.

Investigations into gender portrayals in the mass media, especially television, would do well to take into account audience characteristics (Craig, 1992, 1993; Fiske, 1987; Vigorito \& Curry, 1998). As Craig (1993) argued, television viewing is a gendered activity, and, as such, gendermedia researchers should not neglect the audience as the reader of the television text. Through analyses of television programs and commercials, Craig (1992), noted that gender images are influenced by whether the target audience is male or female. As well, speaking of "gendered television," Fiske (1987) remarked that television programs are customized for particular audiences, which are often divided into "mostly men/boys" or "mostly women/girls." What this means is that "femininity" and "masculinity" may be presented differently to different audiences. Craig has found that television commercials portray gender differently to male and female audiences. Portrayals of men and women in commercials aimed at male weekend sports viewers tend to take traditional forms, what Craig calls "Men's Men" and "Men's Women," whereas portrayals of men and women in commercials aimed at female daytime show viewers tend to take alternative forms, better categorized as "Women's Men" and "Women's Women." Vigorito and Curry (1998) further maintained that media images of gender are only meaningful when it is clear who is actually being exposed to the cultural messages embedded within them. As they analyzed popular magazines directed at male audiences, Vigorito and Curry were not surprised to find images of men and masculinity that reaffirmed traditional hegemonic masculinity. They argued that the mass media, hoping to elicit a positive audience response, tend to present images that support accepted definitions of masculinity and femininity.

Much like televised sport is a gendered genre (Kennedy, 2000), professional wrestling can be considered a gendered form of popular culture entertainment. Professional wrestling's audience consists largely of men and boys, 12 to 34 years of age (Ashley et al., 2000; Jhally \& Katz, 2002; Lemish, 1998); some evidence points to a substantial percentage $(15 \%)$ of male viewers who are 11 years of age or younger (Rosellini, 1999). Based on previous arguments, it might be expected that the messages about manhood presented by televised professional wrestling to its primarily male audience support the cultural ideal form of masculinity.

Two research questions effectively guided the investigation of manhood in professional wrestling: (1) What messages pertaining to masculinity and manhood are revealed by popular televised professional wrestling shows?; (2) How are proof and assertion of manhood accomplished by the men in these shows?

It was believed that answers to these questions would add to the existing literature concerning media representations of gender and gender roles by enriching our understanding of the ways in which messages about manhood and masculinity are formulated and presented by popular television media such as World Wrestling Entertainment (WWE) programs.

\section{Materials and Methods}

\section{The sample}

The sample consisted of the two primary WWE (World Wrestling Entertainment $)^{1}$ television programs, $R A W$ and Smackdown!, as well as monthly pay-per-view events. In total, 118 episodes of WWE programming were recorded and analyzed for messages related to manhood.

\footnotetext{
${ }^{1}$ In Spring 2001, World Championship Wrestling (WCW) and Extreme Championship Wrestling (ECW) amalgamated with the World Wrestling Federation (WWF). In Summer 2002, World Wrestling Federation changed its name to World Wrestling Entertainment (WWE).
} 
$R A W$ is a 2-h WWE program broadcast live on US cable channel TNN (now Spike TV) on Monday nights from 9 to 11 P.M. Fifty-two (52) $R A W$ episodes were recorded in total between August 16, 2001 and August 22, 2002. Smackdown! is a 2-h WWE program taped and then broadcast on network television, primarily UPN, on Thursday nights from 8 to 10 P.M. A total of 54 Smackdown! episodes were recorded during the data collection period. WWE pay-perview events are broadcast live once per month and, on average, are $3 \mathrm{~h}$ in duration. Pay-per-view events are accessible only to subscribers and are not available on regular cable or network television. Because these events are typically extensions of the cable and network wrestling programs, rather than separate programs altogether, they were included in the analysis for continuity. There were 12 pay-per-view wrestling events recorded during the data collection period.

Procedure

Answers to the research questions were achieved through qualitative content analysis, in which themes pertaining to masculinity were discerned by employing techniques of qualitative coding and constant comparison as outlined by Strauss (1987).

Detailed transcripts of the 118 episodes were first subjected to analysis, and all data that clearly pertained to "being a man" were selected for further thematic coding. I then engaged in the process of open, axial, and selective coding (Strauss, 1987) of the "manhood" data in order to reveal particular themes. These themes were thought to comprise messages about manhood or what being a man entails. Techniques of constant comparison (Strauss, 1987) were further employed to ensure that the data fit appropriate theme categories and that theme categories encompassed the full spectrum of data. To establish a theme or message, several examples were required as a way of ensuring that extremes did not unduly impact the overall interpretation. Similar techniques were applied to data that pertained to "proving manhood," "questioning others' manhood," and "emasculation" so that overall themes could be discerned with respect to how proof and assertion of manhood are accomplished by men in these programs.

To illustrate the thematic coding process, I present data from an episode of Smackdown! (01-10-02) where there was one incident identified in which data about "being a man" is clearly apparent:

William Regal challenges Edge to a match at Royal Rumble: "What do you say, Edge? Are you man enough?" (Proof of manhood-physical competition). Edge responds, "Man enough? I'm not the one running around stuffing things down my pants in order to win matches." (Message: Real men win without cheating; Questioning manhood-male genitalia.) "But I guess you need those brass knuckles because you definitely don't have a set of brass balls." (Questioning manhood-male genitalia)

Above, the data reveal the message that real men win without cheating. As there were few clear examples of such a message, it was not included as an overall theme. The data above also reveal examples of proof of manhood through physical competition and questioning manhood by implying lack of male genitalia. Both of these themes were supported by several examples and were included in the overall results.

To be sure, qualitative content analysis is a very subjective enterprise. A researcher cannot be certain that his or her interpretation is the "right" one or that other viewers would interpret the content in the same way. To minimize subjectivity as well as to overcome the limitations of having a single coder, two volunteers, ${ }^{2}$ who were selfidentified regular viewers of WWE programs, were each given transcripts from one episode of Smackdown and one episode of $R A W$; the volunteers were asked to identify what they perceived to be the major messages pertaining to manhood in each episode. The messages identified were compared to those coded by the researcher in order to assess baseline validity and reliability. Agreement was reached in eight out of ten of the messages identified and coded, giving the research a certain degree of confidence in her interpretation of the data. This viewer validation served as a kind of member check (Lindlof, 1995) that is common in qualitative research and is intended to increase the validity and reliability of the research results.

\section{Results}

Messages about manhood

Qualitative analyses revealed that the WWE shows were characterized by important messages concerning manhood. Indeed, there were very clear messages presented by male performers and announcers about what it means to be a man. These messages included the themes of aggression and violence, emotional restraint, and success and achievement, characteristics associated with the dominant hegemonic masculinity.

\footnotetext{
${ }^{2}$ I wish to thank Anthony DiToro and Phillip DeSantis for their valuable assistance in this research project.
} 
Message 1: Real men are aggressive and violent One message that was clearly revealed through the programs was that real men are physically aggressive and violent. There were several examples in which male performers asserted aggression and violence as a purely masculine trait. For example, when the Undertaker confronts Ric Flair about his aggressive attack on him the previous evening, Flair explains it as a masculine response (RAW 02-18-02):

Taker: You hit me in the head with that pipe last night. Flair: That was me just being a man.

Similarly, after being called out by Triple H to compete in a match against him at Summerslam, Shawn Michaels responds with a message reminiscent of a Kenny Rogers' song: "Sometimes you have to fight to be a man." (RAW 08-05-02). Clearly, the message is that physical aggression defines masculinity, defines what being a man is all about.

Moreover, on an episode of Smackdown (01-03-02), Test hits on female performer Torrie Wilson. When she seems uninterested and tells him that she already has a boyfriend, Test does not appear to be too pleased. He tells Torrie: "Why don't you tell your boyfriend, Tajiri, to meet me in the ring later, and I'll show you what a real man's all about." Test's message is simple: Being a man means being physically aggressive, and he intends to defeat Tajiri in competition to prove to Torrie that he's a "real man."

These examples effectively illustrate the message that being a man entails being aggressive and violent. In each case, physical aggression is emphasized as a masculine trait.

Message 2: Men settle things physically Not only are men aggressive and violent, but their response tends to be primarily physical. Men settle debates, differences, confrontations, and personal affronts through physical means.

For example, when Bradshaw and Farooq laugh at Booker $\mathrm{T}$ who complains about not being invited to the premier of Rollerball (SD 10-31-01), Booker T tells them to "lace "em up," indicating that he intends to have a match with them. This suggests that men settle things physically. Booker $\mathrm{T}$ responds to a personal affront by challenging fellow performers to a physical contest.

On an episode of Smackdown (12-13-01), Jeff Hardy confronts Test after he intimidates Lita. He says, "You like intimidating women so bad, why don't you try intimidating me. In the ring." Again, this suggests that men settle things physically. Here, Jeff Hardy and Test are going to settle their differences through physical competition. Similarly, The Rock suggests to Jericho that the way to settle their differences is through physical competition:

The Rock is tired of this mamsy-pansy chicken crap going on between you and The Rock. We settle this one more time before Summerslam, this Monday night on $R A W$. (SD 11-01-01)

Finally, it is certainly clear that men are expected to settle things physically when Commissioner William Regal tells Booker T and Rob Van Dam: "If you want to settle your differences, settle them like sportsmen in the ring tonight." (RAW 11-05-01)

Message 3: A man confronts his adversaries and problems A further message revealed through the programs was that men are confrontational. To express this less violent form of aggression, male performers confronted each other and their problems in a variety of ways.

There were several examples in which manhood entailed confronting an adversary. During an episode of Smackdown (08-03-01), Kurt Angle tells rival Stone Cold Steve Austin to "face him like a man." This suggests that being a man means confronting your adversary. In the context of professional wrestling and elsewhere, a real man faces his opponent. Similarly, announcer Michael Cole asserts that being a man entails confronting your adversary and competing physically: "Well, Booker $\mathrm{T}$ demands all this respect, wants to be (WCW) champion again. Why doesn't he be a man and get in the ring and face The Rock one-onone at Unforgiven?" (SD 09-04-01) Announcer JR also suggests that confronting your adversary is a necessary part of being a man. He says of Booker T: "He should come out of the closet and fight Austin like a man!" (RAW 12-17-01) Not only are men expected to confront their rivals, but they are expected to settle things physically through competition or fist-fight.

Men are also expected to confront their problems. When Debra tells Austin that he needs to go out to the ring and confront the fans about his recent violent actions against Kurt Angle (SD 09-04-01), she is suggesting that part of being a man is to confront personal issues. Austin further reinforces this message when he tells the Memphis crowd: "Stone Cold Steve Austin has a problem, he looks that person right in the eyes, and he settles that problem, because I'm a man's man." (SD 09-20-01) Clearly, manhood involves confronting one's problems as well as one's adversaries.

Message 4: Real men take responsibility for their actions As perhaps a derivative of being confrontational, manhood also entails taking responsibility. The message revealed was that real men take responsibility for their actions. Both the male performers and the announcers effectively disseminated this message about manhood. As The Rock tells Jericho after Jericho's actions cost them a match and the Tag Team championship: "The Rock just wants you to 
be a man and live up and own up to your responsibilities." (RAW 10-08-01) Here, The Rock is suggesting that men recognize and take responsibility for their actions. Likewise, JR suggests that part of being a man entails accepting responsibility when he addresses the firing of fellow announcer Paul Heyman and his subsequent immature behavior:

It's just a sad state of affairs when people aren't man enough to look in the mirror when they have a problem. That's where the answer lies. (SD 11-15-01)

JR suggests that it is Heyman's own fault that he lost his job and that if he was a real man, he would own up to his mistakes and accept responsibility.

In another example, Test tells Jericho to "be a man and apologize" to Stacy Keibler for causing her injury (RAW 02-03-03). Announcer JR remarks that this is "what a man should do. You make a mistake, you just admit it." Again, the message is clear: Real men take responsibility for their actions.

Message 5: Men are not whiners As the classic adage "real men don't cry" suggests, men are expected to exercise emotional restraint, to keep their emotions in check, and to avoid displaying any public show of certain emotions. In short, men are not whiners or cry babies.

There were abundant examples of this masculinity message throughout the WWE programs. On an episode of Smackdown (10-11-01), for example, Kurt Angle throws a temper tantrum after losing a match. Commentator Tazz declares: "You talk about your sore losers here. Crybaby! I'm begging Angle to take it like a man!" Here, Tazz suggests that to be a man means to exercise emotional restraint. Men are not supposed to complain or whine about losing.

In a similar example, announcer Michael Cole comments that Christian, a young male performer, has "got to stop whining about things" and "get in the ring and bust butt" (SD 02-21-02). The message here is two-fold: Not only are men not whiners, but they are expected to be physical rather than emotional.

Moreover, emotional restraint as masculine was emphasized when The Rock shows that he is above getting all worked up over Hogan's deliberate verbal jabs. The Rock agrees to pose with Hogan, and tells him, "The Rock (is) being a man. A picture for your son. No problem." (No Way $O u t$ ). The Rock's message, through his actions and words, is that keeping one's emotions in check is the manly thing to do.

Not only are men not whiners but they are expected to accept defeat gracefully. Real men are not sore losers. This is best illustrated by an example that pits the masculine response against the feminine response. After losing to their father in a Winner-Takes-All match, Shane and Stephanie McMahon respond differently (RAW 11-19-01). Shane readily accepts defeat: "You won and I lost. I lost to the better man." Shane simply leaves the ring, and announcer JR remarks: "Shane's taking it like a man. He lost, he's leaving." In contrast to her brother, Stephanie is emotionally dramatic. She cries, blames her brother for everything, and asks for her father's forgiveness. She is literally carried, kicking and screaming, out of the arena. Here, masculinity is constructed in opposition to femininity. The message revealed through the different responses is that men accept defeat gracefully and bow out, whereas women whine, complain, apologize, and blame others. As JR aptly captures with his remark, men do not give in to emotions but accept things and move on.

It should be noted that despite expectations of emotional restraint, there were emotions deemed acceptable for men to display, primarily the active emotions of anger and frustration. Male performers were frequently described by the announcers as "angry," "livid," "seething," "furious," "irate," "mad," "enraged," and "hot," as well as "frustrated." Also, male performers frequently expressed emotions of anger and frustration during the 2-h shows.

There were several poignant suggestions that the emotions of anger and frustration "naturally" lead to aggression and violence, the primary hegemonic masculine traits. For example, after Triple $\mathrm{H}$ assaults Christian backstage, announcer Michael Cole points out the "anger and frustration in the eyes of Triple H" (SD 01-24-02), and suggests that these emotions are the root of Triple H's aggression. Likewise, commentator Tazz remarks that Austin is "so mad" that "he's going to hurt somebody" (SD 09-04-01), again a suggestion that anger and aggression go hand in hand. Moreover, the suggestion that aggression is a natural outcome of anger and frustration is exemplified by Cole's remark that "the Dudley Boyz have been frustrated and ticked off since losing the Tag Team titles to Spike and Tazz" (SD 01-17-02) as a way of explaining Bubba Ray and D-Von's violent attack on the two in the arena parking lot.

Although men should exercise restraint with respect to emotional displays that are considered more conventionally feminine (e.g., crying, hysteria, whining, complaining), they are encouraged to express emotions of anger and frustration, which complement the masculine trait of aggression and violence.

Message 6: Men are winners Winning and achievement are part of being a man. This was very apparent even in the contrived world of professional wrestling. Male performers who held the championship title were described as "The Man," which suggests that masculinity is synonymous with winning and achievement. For example, JR says of Chris 
Jericho on an episode of $R A W$ (10-22-01): "Jericho is the man. Chris Jericho is the WCW champion." Likewise, JR says of champion The Rock: "Man, what matchup, but The Rock is still the man." (RAW 09-03-01) Clearly, winning and achievement are part of being a man. Holding a major championship title indicates proven masculinity. It is interesting that the same awe does not seem to be applied to female performers who win major championships. Female title holders are not described as "The Woman." Winning and achievement, therefore, are constructed as masculine not feminine.

\section{Proof of Manhood}

In the WWE, men were frequently asked to prove their manhood. For example, the Undertaker effectively asks for proof of manhood when he tells Ric Flair: "You're a man now. I guess you think we're even. I want your ass in the ring at Wrestlemania. We're gonna see what kind of man you are." (RAW 02-18-02) Here, the Undertaker is asking Flair to prove that he is a real man through physical competition. Likewise, Hogan demands proof of manhood from Vince McMahon: "You say you're a man. Well, I say prove it, Vince. Get in the ring and have a match with me tonight." (SD 03-06-03) In another example, Vince McMahon takes it upon himself to show proof of manhood. He tells the New York City crowd: "Flair has a saying - To be the man, you've got to beat the man. Well, Flair, I'm already the man and right now I'm going to prove it." (RAW 01-07-02) In each case men are expected to prove their manhood to other men, which suggests that proof of manhood occurs within the homosocial world of men. Men must show other men that they are, in fact, real men. Men in the WWE attempted to prove and assert their manhood by demonstrating characteristics of the dominant hegemonic masculinity and by questioning the manhood of others.

Proof of manhood through display of aggression was revealed in several examples. On an episode of $R A W(08-$ 20-01), Stephanie McMahon asks Test to "take out" Jericho, telling him "You're the man, and I firmly believe that you can take Chris Jericho out for good tonight." Stephanie is implying that a show of aggression by Test will prove he's a man. Likewise, on the same night, Jericho declares: "(When) Rhyno beat the living hell out of me, he actually showed a true set (of testicles)." Jericho is suggesting that a show of aggression proves Rhyno's manhood. In another example, Vince McMahon tells the Undertaker: "What you did to the Hardyz and Lita, it takes a man to do that. It takes a big man." (SD 12-27-01) Again, this suggests that aggression serves as adequate proof of manhood. Similarly, when the Undertaker says to the Big Show: "Be a man! Walk down the ramp, get in the ring, and fight me!" (SD 01-30-03), he insinuates that to be a man, to prove one's manhood, one must be willing to fight, to be aggressive.

Keeping in tune with male physicality, men in the WWE sought to prove their manhood through physical competition. For example, Commissioner Mick Foley proposes that Rhyno put the US Title on the line against Kurt Angle, and adds "unless he doesn't have the fortitude" (RAW 10-2201) In essence, Foley is asking Rhyno to prove his manhood through physical competition. Likewise, when JR comments that "Booker $\mathrm{T}$ has a chance to prove what kind of man he is, here and now, one-on-one with The Rock" (SD 09-20-01), he is suggesting that one way to prove sufficient manhood is through physical competition.

In two other examples, male performers challenged others to wrestling matches by insinuating that it was a way to prove their manhood. William Regal challenges Edge to a match at Royal Rumble: "What do you say, Edge? Are you man enough?" (SD 01-10-02) Similarly, Scott Hall challenges Stone Cold Steve Austin to a match at Wrestlemania: "I'm a man. And I'm all man. So, the question is, Stone Cold, are you a man?" (RAW 02-25-02)

Winning was another way to prove sufficient masculinity. Often it was the case that the winner of a match was described as "the better man," suggesting that proof of manhood is wrapped up in victory. The rivalry between The Rock and Chris Jericho is a good example of how winning serves as proof of manhood. During the month leading up to the October pay-per-view No Mercy, it is suggested several times that Jericho "can't win the big one" (RAW 10-15-01), that he is unable to win a major championship title. To prove he can be a winner (and hence a real man), Jericho challenges The Rock to a championship match at No Mercy. Even after Jericho wins, The Rock requires further proof of Jericho's manhood by showing that he can be victorious again:

You may have won the big one once. Once. But remember, and never forget, The Rock has been winning big ones for years. (RAW 10-29-01)...Show The Rock you can win the big one one more time. (SD 11-01-01)

Proof of adequate manhood, therefore, requires that men show that they are winners.

Questioning others' manhood Men in the WWE asserted their manhood by questioning the manhood of others. A male performer's manhood was questioned when it was suggested that he lacked the characteristics of the dominant hegemonic masculinity or when he was compared to a woman.

As an example, when Triple $\mathrm{H}$ finds police officers guarding Vince McMahon's office where Kurt Angle has 
sought refuge, he remarks that "Angle's a bigger wuss than I thought." (RAW 02-04-02) Triple H questions Angle's manhood by implying that he lacks courage, that he runs to safety behind guarded doors. Similarly, the Undertaker questions Michael Cole's manhood by implying that he lacks the appropriate masculine attribute-courage: "What's wrong, Cole? I sense fear. Do you fear me? "Cause I like that." (RAW 02-04-02) Moreover, when Christian throws a temper tantrum and announces that he quits, Cole comments sarcastically: "Well, that's a manly way of doing it." (SD 02-21-02) Here, Cole questions Christian's manhood. By not exercising emotional restraint and not showing toughness by sticking it out, Christian's masculinity is suspect. Furthermore, Jericho questions Flair's manhood not only by implying that he lacks courage but by comparing him to a woman:

I saw you quivering in your boots. I saw you quivering like a scared little girl. What kind of man are you anyways, Flair? (SD 02-14-02)

Male performers also effectively questioned each other's manhood by implying that they were missing the requisite male genitalia. Jericho asks Test: "How can a man whose name is short for testicles have absolutely none?" (RAW 08-20-01); The Rock declares: "Clearly Chris Jericho is a man who has no strudel (penis)" (RAW 12-24-01); and Edge tells William Regal: "I guess you need those brass knuckles, because you definitely don't have a set of brass balls." (SD 01-10-02)

Questioning one's manhood requires a response and often proof that one is, indeed, a man, as the following exchange between Kurt Angle and Shane McMahon illustrates (RAW 09-24-01):

Angle: Shane McMahon, well Shane, I don't think you have a strudel.

McMahon: Not only do I have a strudel, but I got the whole damn bakery down there!

Shane McMahon challenges Kurt Angle to a match for the WWE championship. Angle accepts and remarks: "And we'll see if you have a strudel or a twinkie!" Not only is having a penis a measure of manhood, but when it is suggested that Shane McMahon doesn't have one, this calls for a challenge to prove that he has a penis and is therefore a man.

Emasculation Men in the WWE also asserted their manhood by emasculating or feminizing other men. This was accomplished first through physical domination. As an example, Tazz complains about the brutal beating he received from Stone Cold Steve Austin, lamenting that Austin "destroyed my manhood." (SD 08-16-01) Clearly,
Austin's physical domination of Tazz served to emasculate him; his manhood was not only questioned but destroyed. Similarly, Shane McMahon shows a clip from $R A W$ on Smackdown (08-16-01) in which Booker $\mathrm{T}$ physically dominates The Rock through post-match aggression. Shane comments to the live audience: "There's your beloved Rock. Look at him," and then he proclaims Booker T "the man." In effect, Shane is suggesting that Booker $\mathrm{T}$ has emasculated The Rock by rendering him vulnerable and weak. Through physical domination, Booker $\mathrm{T}$ has asserted his own manhood, which makes him "the man."

Punches to the groin, known in professional wrestling as "low blows," were a further way of showing dominance over other men. The "low blow" effectively reaffirms masculinity by emasculating other men. After all, what is more emasculating than being taken down by being hit in one's most vulnerable spot? Throughout the programs, the low blow was a common manoeuvre used by male performers to establish dominance over their opponents. As a testament to its emasculating effects, the announcers typically made snide side remarks. For example, after Jericho receives a low blow, Paul Heyman comments, "If you ask Chris Jericho how that feels, he'll say (uses a high pitched voice) it really, really hurts." (RAW 09-10-01) Similarly, Heyman remarks after Bubba Ray Dudley delivers a low blow to the Big Show: "That's the end of the Big Show's love life, I'd say." (RAW 09-03-01)

Men also attempted to emasculate other men by employing feminizing terms. The Rock calls Jericho a "punk-ass bitch" (RAW 11-12-01), Kurt Angle calls Christian a "pretty boy" (RAW 10-22-01), and Bradshaw refers to Billy and Chuck as "ladies." (SD 02-21-02) The crowd even gets in on this technique by chanting, "Shane's a pussy!" (RAW 1008-01; RAW 10-29-01) Feminizing other men in this manner served to reaffirm one's own masculinity.

\section{Discussion}

Six important messages about manhood were revealed by the WWE programs: (1) Real men are aggressive and violent, (2) men settle things physically, (3) a man confronts his adversaries and problems, (4) real men take responsibility for their actions, (5) men are not whiners, and (6) men are winners. These messages support the dominant culturally ideal hegemonic form of masculinity by emphasizing aggression and violence, emotional restraint, and success and achievement as desirable masculine traits. Moreover, proof and assertion of manhood were effectively accomplished by demonstrating characteristics of the dominant hegemonic masculinity (aggression, physical competition, success) and by questioning the manhood of other men. 
It can be argued that media messages that promote hegemonic masculinity have important implications. First, as part of the socializing culture that encompasses both television and sport, televised professional wrestling may, arguably, contribute to the gender role socialization of young viewers through its messages. The messages about manhood imparted by WWE performers and announcers may act as scripts that convey appropriate masculine behavior and attitudes and hint at what being a man is all about. Young viewers exposed to these messages may therefore learn that masculinity entails being aggressive and confrontational and that being a man means being a winner, not a whiner. Such a message may have inadvertent implications if carried to a context where a viewer finds himself the "loser" in a confrontation and may contribute to feelings of not being able to measure up to perceived societal standards of manhood.

Though research suggests that television exerts a powerful socializing influence on viewers regarding attitudes toward gender and gender roles (Andersen, 1997; Liebert \& Sprafkin, 1988; Spangler, 1992; Witt, 2000), it is difficult to assess within the context of the current study precisely what gender role socialization effects televised professional wrestling may have on its viewers. Nevertheless, given the primary male audience of professional wrestling programs, it is important to consider the messages about manhood promoted and their potential socializing effects. Subsequent research should focus on audience composition and the reading of professional wrestling events as a way of investigating gender role socialization through media representations.

It should also be kept in mind that socialization via media representations is not simply a one-way process. It can be argued that people select the kinds of television programs they watch, and selection may be based on expectations and preference for a certain kind of content. Those who choose to watch professional wrestling programs may do so because the content, including its representations of masculinity and femininity, appeals to them and perhaps even fits in with individual notions of what being man or being a woman is all about. In this sense, a sort of self-socialization process may be taking place, with television portrayals simply reinforcing established gender role expectations.

By emphasizing the dominant hegemonic masculinity, the messages about manhood presented by WWE programs leave little room for alternative expressions of masculinity. Alternative masculinities, such as a non-violent, emotionally centered masculinity, are effectively masked, and even shunned, within the context of professional wrestling. By highlighting the characteristics of masculinity associated with White, heterosexual, middle-class men, the WWE messages stifle both minority and homosexual versions of manhood, which may inadvertently foster racist and/or homophobic attitudes. It is interesting that both White (e.g., Triple H, Kurt Angle, Stone Cold Steve Austin) and minority (e.g., The Rock, Booker T, D-Von Dudley) male performers were involved in the dissemination of hegemonic manhood messages, which suggests that the dominant masculinity extends beyond racial boundaries. However, the heterosexual ideal remains consistent, and it marginalizes homosexual masculinities.

In addition, emasculation techniques employed to assert one's manhood clearly emphasize that conventional femininity and traditional feminine traits are not desirable. This promotes a dichotomy between men-masculinity and women-femininity, which may further lead to misogynist attitudes. Whereas the focus of the current study was on men and masculinity, it is recommended that portrayals of women be investigated within the context of professional wrestling in order to address the potential effects of such images on the male viewing audience.

The promotion of a hegemonic version of manhood through mediated messages not only stifles alternative masculinities, but may have unintended consequences for men who internalize this dominant version. As Clatterbaugh (1995) has argued, many of the dominant masculine traits place restrictive limits on men, and may contribute to psychological health problems (Good et al., 2002; Good, Sherrod, \& Dillon, 2000; Nicholson, 1993) as well as physical injury and early death (Pollack, 1998; Thompson, 1991). Moreover, adherence to the dominant masculinity may provide erroneous justification for physical and sexual aggression against women (Hills, 1995; Russell, 1975). Concern regarding the potentially negative consequences of adhering to hegemonic masculinity has led some men's studies scholars to call for the media to provide alternative images of men that reflect various or diverse expressions of manhood (Good et al., 2002).

To be sure, not all of the messages presented in the WWE programs are negative. Despite the emphasis on physical aggression and emotional stoicism, the messages also encourage taking responsibility, accepting defeat gracefully, and success through winning, which are laudable masculine traits, though these messages could have negative implications if taken to an extreme. For example, messages that emphasize winning at all costs could promote cheating, unnecessary risk-taking, violence, and willing acceptance of pain and injury.

Furthermore, it is important to consider that professional wrestling, as a popular culture medium, may also contain some degree of gender parody, thereby providing a cultural critique of society's ideal conceptions of masculinity and femininity. To shed light on this important issue, it is recommended that the extent to which viewers recognize and interpret possible gender parodies in televised professional wrestling be investigated. 
Finally, media messages that concern gender must take into account the success-driven economic goals of television. According to Craig (1992), as a form of mainstream popular culture, television generally acts to reinforce the status quo, which guarantees a certain degree of programming success. Gender images and stereotypes therefore serve to emphasize the culturally ideal versions of masculinity and femininity that best fit the target audience. In the case of professional wrestling, the target audience is adolescent boys and young adult men. Even accounting for a diverse group of men who watch professional wrestling shows, the formula for television success nevertheless dictates that images of men and women be presented that do not stray too far from the mainstream in order to ensure that the shows appeal to the widest possible audience. Given the necessity of television programming to cater to the target audience, it is no surprise that hegemonic masculinity is dominant in professional wrestling programs. In this way, televised professional wrestling reinforces the culturally ideal hegemonic masculinity through its programming in order to please an audience that both expects and demands this version.

\section{Conclusion}

The messages about manhood revealed by World Wrestling Entertainment (WWE) programs and pay-per-view events support the hegemonic masculine ideal. Such messages have implications for the potential gender role socialization of a largely male wrestling audience, as conventional presentations mask and stifle alternative masculinities, especially homosexual versions. However, the potential socializing effects of televised professional wrestling are difficult to assess without further research that takes into account audience composition and the reading of gender by diverse viewers.

Furthermore, it must be kept in mind that presentations of traditional hegemonic masculinity in professional wrestling may be an attempt to parody contemporary gender roles and therefore to offer a critique of societal ideals. At the same time, such gender parodies may serve to reaffirm rather than question conventional masculinity and femininity. Investigation of the function and interpretation of gender parody in professional wrestling is recommended to shed light on gender role stereotyping in popular culture media representations.

Finally, taking into account the formula for television success, hegemonic masculine presentations in professional wrestling may reflect an attempt by producers to appeal to the target audience and to ensure program success. Mediagender research that takes into account the audience is necessary to further the understanding of gender and gender role portrayals in popular culture media.

\section{References}

Albano, L., Sugar, B. R., \& Woodson, R. (1999). The complete idiot's guide to professional wrestling. New York: Alpha.

Andersen, M. L. (1997). Thinking about women: Sociological perspectives on sex and gender. Boston: Allyn \& Bacon.

Anderson, D., \& Hamilton, M. (2005). Gender role stereotyping of parents in children's picture books: The invisible father. Sex Roles, 52, 145-151.

Ashley, F. B., Dollar, J., Wigley, B., Gillentine, J. A., \& Daughtrey, C. (2000). Professional wrestling fans: Your next-door neighbors. Sport Marketing Quarterly, 9, 140-148.

Atkinson, M. (2002). Fifty million viewers can't be wrong: Professional wrestling, sports-entertainment, and mimesis. Sociology of Sport Journal, 19, 47-66.

Basow, S. A. (1992). Gender stereotypes and roles. Pacific Grove, CA: Brooks/Cole.

Beal, C. (1994). Boys and girls: The development of gender roles. New York: McGraw-Hill.

Brannon, R. (1976). The male sex role - and what it's done for us lately. In R. Brannon \& D. David (Eds.), The forty-nine percent majority (pp. 10-25). Boston: Addison-Wesley.

Brittan, A. (1989). Masculinity and power. New York: Blackwell.

Butler, J. (1995). Melancholy gender/refused identification. In M. Berger, B. Wallis \& S. Watson (Eds.), Constructing masculinity (pp. 21-36). New York: Routledge.

Butryn, T. M. (2003). Wrestling with manhood: Boys, bullying, and battering. Sport Psychology, 17, 487-489.

Cherry, E. (2002, April). The toughest SOBs on cable: Gender roles in professional wrestling. Paper presented at the meeting of the Southern Sociological Society, Atlanta, Georgia.

Clark, R., Guilmain, J., Saucier, P. K., \& Tavarez, J. (2003). Two steps forward, one step back: The presence of female characters and gender stereotyping in award-winning picture books between the 1930s and the 1960s. Sex Roles, 49, 439-449.

Clatterbaugh, K. (1995). Contemporary perspectives on masculinity. In E. D. Nelson \& B. W. Robinson (Eds.), Gender in the 1990s: Images, realities, and issues (pp. 525-533). Toronto: Nelson Canada.

Communication Studies 298 (2000). A night with the narcissist and the nasty boys: Interpreting the World Wrestling Federation. Qualitative Inquiry, 6, 526-545.

Connell, R. W. (1987). Gender and power: Society, the person, and sexual politics. Stanford, CA: Stanford University Press.

Craig, S. (1992). Men's men and women's women: How TV commercials portray gender to different audiences. In R. Kemper (Ed.), Issues and effects of mass communication: Other voices (pp. 89-100). San Diego, CA: Capstone.

Craig, S. (1993). Selling masculinities, selling femininities: Multiple genders and the economics of television. Mid-Atlantic Almanack, $2,15-27$.

Diekman, A. B., \& Murnen, S. K. (2004). Learning to be little women and little men: The inequitable gender equality of non-sexist children's literature. Sex Roles, 50, 373-385.

Dietz, T. L. (1998). An examination of violence and gender role portrayals in video games. Sex Roles, 38, 425-442.

Ditsworth, D. (2001). The portrayal of gender in the children's program Sesame Street and its effect on the intended audience. New Jersey Journal of Communication, 9, 214-226.

Donaldson, D. (1993). What is hegemonic masculinity? Theory and Society, 22, 643-657.

Durkin, K. (1985). Television and sex role acquisition 1: Content. British Journal of Social Psychology, 24, 101-113.

Dworkin, S. L., \& Wachs, F. L. (2000). The morality/manhood paradox: Masculinity, sport, and the media. In J. McKay, M. 
Messner, \& D. Sabo (Eds.), Masculinity, gender relations, and sport (pp. 47-66). Newbury Park, CA: Sage.

Evans, L., \& Davies, K. (2000). No sissy boys here: A content analysis of the representation of masculinity in elementary school reading textbooks. Sex Roles, 42, 255-270.

Fiske, J. (1987). Television culture. New York: Methuen.

Ganahl, D. J., Prinsen, T. J., \& Netzley, S. B. (2003). A content analysis of prime-time commercials: A contextual framework of gender representation. Sex Roles, 49, 545-551.

Gauntlett, D. (2002). Media, gender, and identity: An introduction. New York: Routledge.

Gilmore, D. D. (1990). Manhood in the making: Cultural concepts of masculinity. New Haven, CT: Yale University Press.

Good, G. E., Porter, M. J., \& Dillon, M. G. (2002). When men divulge: Portrayals of men's self-disclosure in prime time situation comedies. Sex Roles, 46, 419-427.

Good, G. E., Sherrod, N. B., \& Dillon, M. G. (2000). Masculine gender role stressors and men's health. In R. Eisler \& M. Hersen (Eds.), Handbook of gender, culture, and health (pp. 63-81). Mahwah, NJ: Erlbaum.

Gooden, A. M., \& Gooden, M. A. (2001). Gender representation in notable children's picture books: 1995-1999. Sex Roles, 45, 89101.

Haley, K. (2003, February 24). Inside RAW revolution: RAW helped turn pro wrestling into a phenomenon that WWE has begun to export around the world. Multichannel News, p. 53A.

Hanke, R. (1992). Redesigning men: Hegemonic masculinity in transition. In S. Craig (Ed.), Men, masculinity, and the media (pp. 185-198). Newbury Park, CA: Sage.

Hanke, R. (1998). The "mock-macho" situation comedy: Hegemonic masculinity and its reiteration. Western Journal of Communication, 62, 74-93.

Hills, S. L. (1995). Rape and the masculine mystique. In E. D. Nelson \& B. W. Robinson (Eds.), Gender in the 1990s: Images, realities, and issues (pp. 443-454). Toronto: Nelson Canada.

Hopkins, P. D. (1996). Gender treachery: Homophobia, masculinity, and the threatened identities. In L. May, R. Strikwerda, \& P. D. Hopkins (Eds.), Rethinking masculinity: Philosophical explorations in light of feminism (pp. 95-115). Lanham, MD: Rowman \& Littlefield.

Jhally, S., \& Katz, J. (2002). Wrestling with manhood [Video]. Northampton, MA: Media Education Foundation.

Kaufman, M. (1995). The construction of masculinity and the triad of men's violence. In M. Kimmel \& M. Messner (Eds.), Men's lives (2nd ed.) (pp. 13-25). Boston: Allyn \& Bacon.

Kennedy, E. (2000). Bad boys and gentlemen: Gendered narrative in televised sport. International Review for the Sociology of Sport, $35,59-73$.

Kimmel, M. (1990). After fifteen years: The impact of the sociology of masculinity on the masculinity of sociology. In J. Hearn \& D. Morgan (Eds.), Men, masculinities, and social theory (pp. 93109). London: Unwin Hyman.

Kimmel, M. (1999). Masculinity as homophobia: Fear, shame, and silence in the construction of gender identity. In J. A. Kuypers (Ed.), Men and power (pp. 84-103). Halifax, Nova Scotia: Fernwood.

Koivula, N. (2001). Perceived characteristics of sports categorized as gender-neutral, feminine, and masculine. Journal of Sport Behavior, 24, 377-394.

Lemish, D. (1998). Girls can wrestle too: Gender differences in the consumption of a television wrestling series. Sex Roles, 38, 833849.

Liebert, R. M., \& Sprafkin, J. (1988). The early window: The effects of television on children and youth. New York: Pergamon.

Lindlof, T. R. (1995). Qualitative communication research methods. Thousand Oaks, CA: Sage.
Mazer, S. (1998). Professional wrestling: Sport and spectacle. Jackson, MS: University Press of Mississippi.

Messner, M. (1987). Male identity in the life course of the jock. In M. Kimmel (Ed.), Changing men (pp. 53-67). Newbury Park, CA: Sage.

Messner, M. (1992). Power at play. Boston: Beacon.

Messner, M. (2000). The televised sports manhood formula. Journal of Sport and Social Issues, 24, 380-394.

Messner, M., Hunt, D., \& Dunbar, M. (2001). Boys to men, sports media: Messages about masculinity. Children Now. Retrieved July 15, 2002 from http://www.childrennow.org/Media/boystomen/ report-sports.html.

Nicholson, J. (1993). Men and women: How different are they? Oxford: Oxford University Press.

Ogletree, S. M., Martinez, C. N., Turner, T. R., \& Mason, B. (2004). Pokemon: Exploring the role of gender. Sex Roles, 50, 851-859.

Pollack, W. S. (1998). Real boys: Rescuing our sons from the myths of boyhood. New York: Random House.

Rosellini, L. (1999, May 17). Lords of the ring. US News and World Report 52,

Russell, D. (1975). The politics of rape. New York: Stein and Day.

Sabo, D. F., \& Panepinto, J. (1990). Football ritual and the social reproduction of masculinity. In M. A. Messner \& D. F. Sabo (Eds.), Sport, men, and the gender order: Critical feminist perspectives (pp. 115-126). Chicago: Human Kinetics.

Scharrer, E. (2001). Men, muscles, and machismo: The relationship between television violence exposure and aggression and hostility in the presence of masculinity. Media Psychology, 3, 159-188.

Schnirring, L. (2000). Pain and injury are real in professional wrestling. Physician and Sportsmedicine, 28, 15-18.

Schoenberg, B. M. (1993). Growing up male: The psychology of masculinity. Westport, CT: Begin \& Garvey.

Seidman, S. A. (1999). Revisiting sex role stereotyping in MTV videos. International Journal of Instructional Media, 26, 11-22.

Soulliere, D. M. (2005). Masculinity on display in the squared circle: Constructing masculinity in professional wrestling.Electronic Journal of Sociology at http://www.sociology.org/content/2005/ tier1/soulliere.html.

Spangler, L. C. (1992). Buddies and pals: A history of male friends on prime time television. In S. Craig (Ed.), Men, masculinity, and the media (pp. 93-110). Newbury Park, CA: Sage.

Strauss, A. (1987). Qualitative analysis for social scientists. New York: Cambridge University Press.

Stroud, S. R. (2001, February). The ideology of the body-slam: A critical examination of professional wrestling. Paper presented at the meeting of the Western States Communication Association, Media Studies Division, Coeur d'Aline, Idaho. Retrieved June 21, 2001 from http://members.aol.com/stroud76/wrestling.htm.

Thompson, C. (1991). We should reject traditional masculinity. In C. Thompson (Ed.), To be a man: In search of the deep masculine (pp. 4-10). New York: Tarcher.

Thornton, A. D. (1993). The accomplishment of masculinities: Men and sports. In T. Haddad (Ed.), Men and masculinities (pp. 121162). Toronto: Canadian Scholars'.

Toch, H. (1998). Hypermasculinity and prison violence. In L. H. Bowker (Ed.), Masculinities and violence (pp. 168-178). Newbury Park, CA: Sage.

Towbin, M. A., Haddock, S. A., Zimmerman, T. S., Lund, L. K., \& Tanner, L. R. (2003). Images of gender, race, age, and sexual orientation in Disney feature-length animated films. Journal of Feminist Family Therapy, 15, 19-44.

Vigorito, A. J., \& Curry, T. J. (1998). Marketing masculinity: Gender identity and popular magazines. Sex Roles, 39, 135-152.

Witt, S. D. (2000). The influence of television on children's gender role socialization. Childhood Education, 76, 322-324. 